\title{
Assessment of cancer risk in two rural West Texas communities using anthropometrics, diet, and physical activity
}

\author{
Natalie Masis ${ }^{1 *}$, Debra B. Reed ${ }^{2}$, Barent N. McCool $^{2}$, Jamie A. Cooper ${ }^{2}$, Conrad Lyford $^{3}$ \\ ${ }^{1}$ Former M.S. Nutritional Sciences Graduate Student, Texas Tech University, Lubbock, USA; \\ *Corresponding Author: masis2@illinois.edu \\ ${ }^{2}$ Department of Nutrition, Hospitality and Retail Management, Texas Tech University, Lubbock, USA \\ ${ }^{3}$ Department of Agricultural \& Applied Economics, Texas Tech University, Lubbock, USA
}

Received 16 April 2013; revised 17 May 2013; accepted 28 May 2013

Copyright (C) 2013 Natalie Masis et al. This is an open access article distributed under the Creative Commons Attribution License, which permits unrestricted use, distribution, and reproduction in any medium, provided the original work is properly cited.

\begin{abstract}
Cancer risks in the United States are linked to undesirable dietary and physical activity habits that may be more common in rural communities. This study assessed the cancer risk in two rural West Texas communities through anthropometrics, diet, and physical activity measures ( $n=$ 374). No significant relationships were found between body mass index (BMI) and waist circumference (WC) with consumption of fruits, vegetables, whole grains, and sugar-sweetened beverages; however, data showed significant negative associations between $\mathrm{BMI}$ and $\mathrm{WC}$ and physical activity. Over $58 \%$ of the sample was unaware of the link between obesity and cancer risk. Further evaluation of cancer risk in rural communities is needed to develop effective interventions and reduce health disparities.
\end{abstract}

Keywords: Nutrition; Obesity; Cancer Risk; Rural Communities

\section{INTRODUCTION}

The American Cancer Society estimates that there will be about 580,350 cancer deaths in the United States (US) for 2013, and among these, about one-quarter to onethird will be attributed to being overweight or obese, physical inactivity, and poor nutrition [1]. According to a review by Tai-Seale and Chandler (2003), obesity seems to be most severe in rural areas [2]. People in rural areas may face greater cancer risk because of the higher prevalence of undesirable diet and physical activity behaviors that contribute to obesity [3]. However, very little research has been conducted to understand the risk profile of those residing in rural communities to identify factors that may lead to cancer risk, and to identify intervention strategies to reduce these risks. The reasons why there may be a higher prevalence of obesity in rural areas is unclear, but challenges such as fewer prevention and treatment facilities, the distances needed to travel to reach them, limited access to grocery stores and healthier food alternatives, limited access to physical activity options, and cultural challenges may put people living in these areas at higher risks $[2,4]$.

A diet high in fruits, vegetables, and whole grains may be beneficial in protecting the body against DNA damage and mutations which are precursors to cancer initiation [5]. However, many Americans do not meet the recommended intakes of these food groups [6]. Only $32.5 \%$ of adults reported consuming 2 or more servings of fruit per day and even fewer reported consuming 3 or more servings of vegetables per day (26.3\%) based on BRFSS data from 2009 [7]. Recommendations note that at least half of the total grain intake should be whole grains, but less than five percent of Americans consume the minimum recommended amount of whole grains [6]. Thus, although fruits, vegetables, and whole grains have beneficial health effects, they are consumed well below the recommended levels. Conversely, sugar-sweetened beverage consumption in the US is quite high. Sugar-sweetened soft drinks contribute $7.1 \%$ of total energy intake in the US diet [8].

The Dietary Guidelines for Americans, 2010 recommends 150 minutes of moderate-intensity aerobic activity per week for adults to maintain a healthy body weight [6]. Maintaining a healthy level of physical activity may help in the reduction of some cancers [9]. Disparities in physical activity levels exist in urban versus rural settings due to the different characteristics of the environment, such 
as fewer sidewalks and parks and decreased access to recreational facilities, all of which may contribute to lower physical activity levels in rural dwellers [10]. The differences in physical inactivity levels are more apparent between urban and rural areas in the South compared to other investigated areas of the US such as the Midwest and Northeast. This supports the need to study Southern rural communities to address issues that are most relevant for them [11].

The purpose of this study was to examine the characteristics of a sample from two West Texas rural communities in relation to factors that may influence their cancer risk such as consumption of fruits, vegetables, whole grains, and sugar-sweetened beverages, levels of physical activity and anthropometrics including body mass index (BMI) and waist circumference (WC). The goals were to evaluate the profile of these rural communities and develop an understanding of factors that may contribute to increased cancer risk, and therefore should be addressed through intervention. It was hypothesized that higher BMI and WC would be correlated with low fruit, vegetable and whole grain intake, high sugar-sweetened beverage consumption, and decreased levels of physical activity.

\section{METHODS}

\subsection{Sample}

The sample in this study included the baseline (preintervention) participants in a larger study, "A PublicPrivate Partnership for Cancer Prevention in Rural Communities," funded by the Cancer Prevention and Research Institute of Texas (CPRIT). The study was based in the rural West Texas communities of Muleshoe and Dalhart.

The data for this study were collected in the summer of 2011 from 225 participants in Muleshoe and 157 participants from Dalhart. The population of Dalhart is about 7237 (17\% - 30\% estimated to be Hispanic) with a poverty rate of $9 \%-15 \%$ [12]. The population of Muleshoe is about 4571 (17\% - 50\% estimated to be Hispanic) with a poverty rate of $17 \%-23 \%$ [12]. Inclusion criteria for the study was anyone at least 18 years of age who was currently living in Muleshoe or Dalhart. The Texas Tech University Human Research Protection Program approved this study, and informed written consent was obtained from all participants.

\subsection{Anthropometrics and Health Assessment Survey}

The physical measurements of height, weight, and WC along with demographics were taken by trained staff. Height was measured using a stadiometer (HM200P PortStad, Portable Stadiometer-WMFS), and weight was measured using a precision scale (UC-321 Pro FIT Precision Scale, 350lb capacity). BMI was calculated by dividing the participant's weight (in kilograms) by their height (in meters) squared [13]. WC was measured using a measure tape where we asked participants to lift their shirts to expose their abdomen region, and the tape was wrapped around the top of their hip bone, parallel to the ground [13]. BMI categories for underweight, normal, overweight, and obese and WC categories for normal and high risk groups were determined using CDC criteria [13].

Participants completed a two-part health assessment containing two surveys, which were available in English and Spanish. First, the Nutrition and Health Practices Survey focused on the participant's health practices; attitudes toward and perceptions of cancer and cancer risk factors; and food practices. The survey had demographic questions from the Behavioral Risk Factor Surveillance Survey (BRFSS) 2010 Survey (questions 12.6, 12.7, 12.8, and 12.10) [14]. The other questions of the survey related to food, physical activity, and other health behaviors were created by the research team. All questions were pretested at a local supermarket in Lubbock, Texas that was selected so that the survey could be presented to respondents where English might be their second language. After observing and talking to 30 respondents who completed the survey, the team made changes to the survey to clarify questions and response options before the final version was prepared.

The second survey was the AIM-HI Fitness Inventory which was previously used for the Americans in Motion-Healthy Interventions (AIM-HI) research study, conducted by the American Academy of Family Physicians (AAFP) [15]. It contains questions related to physical activity such as "How many times a week do you go for a brisk walk of 10 minutes or more?" and food intake, such as "How many sugary drinks (like regular soft drinks, sweet tea or fruit flavored drinks) do you drink each day?" After completing the data collection, all participants were given educational materials regarding the risk factors for cancer including information about obesity, nutrition, and physical activity and were also given a $\$ 20$ gift card to the local supermarket.

\subsection{Data Analyses}

Descriptive analyses were performed to determine the characteristics of the participants related to race, age, gender, marital status, education, previous cancer diagnosis, income, BMI, WC, and dietary intake of fruits, vegetables, whole grains, and sugar-sweetened beverages. Spearman's correlation and chi-square tests were used to determine the relationship between BMI and WC with reported intake of fruits, vegetables, whole grains, and sugar-sweetened beverages, as well as physical activity 
level. Results were considered significant with $\mathrm{P}<0.05$. Statistical analyses were performed with IBM SPSS Statistics, version 20.0 (IBM Corporation, Somers, NY).

\section{RESULTS}

In the initial data collection, there were 382 participants from Muleshoe and Dalhart. However, after excluding participants who did not provide their age, who were under the age of 18 years, or who were pregnant, the total number of participants was 374. Participants were predominantly female $(66.6 \%)$ and white $(57.8 \%)$ or Hispanic $(38.5 \%)$ with almost $50 \%$ being 50 years of age or older (Table 1). Most participants fell in the overweight or obese categories $(80.2 \%)$ with $46.0 \%$ being in the obese category, and only $18.7 \%$ of the participants were in the normal BMI category.

BMI categories were further analyzed by gender and race (data not shown). Chi-square tests did not show statistically significant differences indicating that BMI categories were independent of gender and race. For males $(\mathrm{N}=125), 83.2 \%$ were considered overweight or obese, and for females $(\mathrm{N}=249), 78.7 \%$ were considered to be overweight or obese. With regard to race, $84 \%$ of Hispanics were overweight or obese, and $78.7 \%$ of whites were overweight or obese.

The participants' attitudes and awareness of cancer risks were evaluated using data from the Nutrition and Health Practices Survey (Table 2). The majority of the participants noted that getting sunburned (93.6\%), chewing tobacco $(96.3 \%)$, and smoking tobacco products

Table 1. Participant demographic and physical characteristics $(\mathrm{N}=374)$.

\begin{tabular}{lc}
\hline Characteristics & Percent or mean (SD) \\
\hline Age (years) & $50.11(18.47)$ \\
Sex, female & $66.6 \%$ \\
Race & \\
Hispanic & $38.5 \%$ \\
White & $57.8 \%$ \\
Other Responses & $3.7 \%$ \\
Education & \\
High school or less & $53.5 \%$ \\
College degree or some college & $44.1 \%$ \\
No response & $2.4 \%$ \\
Household income & \\
Less than $\mathbf{\$ 2 0 , 0 0 0}$ & $34.5 \%$ \\
\$20,000 - \$75,000 & $50.2 \%$ \\
Greater than $\$ 75,000$ & $12.3 \%$ \\
No response & $2.9 \%$ \\
Body mass index (kg/m $\left.{ }^{2}\right)$ & $30.67(6.96)$ \\
Underweight & $1.1 \%$ \\
Normal & $18.7 \%$ \\
Overweight & $34.2 \%$ \\
Obese & $46.0 \%$ \\
Waist Circumference (meters) & $1.02(0.176)$ \\
\hline
\end{tabular}

Table 2. Participants' attitudes and awareness of cancer risks $(\mathrm{N}=374)$.

\begin{tabular}{lcccc}
\hline $\begin{array}{l}\text { Survey question of } \\
\text { whether item causes } \\
\text { cancer }\end{array}$ & $\begin{array}{c}\text { Yes } \\
\mathbf{( \% )}\end{array}$ & $\begin{array}{c}\text { No } \\
\mathbf{( \% )}\end{array}$ & $\begin{array}{c}\text { Don't } \\
\text { Know } \\
\mathbf{( \% )}\end{array}$ & $\begin{array}{c}\text { No } \\
\text { Response } \\
\mathbf{( \% )}\end{array}$ \\
\hline $\begin{array}{l}\text { Drinking tap water } \\
\text { Use of tanning beds }\end{array}$ & 18.4 & 54.5 & 26.5 & 0.5 \\
$\begin{array}{l}\text { Getting sunburned } \\
\text { Being overweight }\end{array}$ & 93.6 & 5.1 & 9.6 & 0.3 \\
$\begin{array}{l}\text { Drinking excessive } \\
\text { quantities of alcohol }\end{array}$ & 57.5 & 15.2 & 27.0 & 0.3 \\
$\begin{array}{l}\text { Chewing } \\
\text { tobacco/using snuff }\end{array}$ & 96.3 & 1.1 & 2.4 & 0.3 \\
$\begin{array}{l}\text { Smoking tobacco } \\
\text { products }\end{array}$ & 98.7 & 0.3 & 0.8 & 0.3 \\
$\begin{array}{l}\text { Drinking large } \\
\text { quantities of caffeine }\end{array}$ & 19.5 & 31.6 & 48.7 & 0.3 \\
\hline
\end{tabular}

Table 3. Intake of fruits, vegetables, and whole grains and physical activity behaviors $(\mathrm{N}=374)$.

\begin{tabular}{|c|c|}
\hline Characteristics & N (\%) \\
\hline \multicolumn{2}{|c|}{$\begin{array}{l}\text { How many servings of fruits or } \\
\text { vegetables do you eat each day? }\end{array}$} \\
\hline 5 or more & $24(6.4)$ \\
\hline 3 to 4 & $145(38.8)$ \\
\hline 2 or less & $203(54.3)$ \\
\hline No response & $2(0.5)$ \\
\hline \multicolumn{2}{|c|}{$\begin{array}{l}\text { How many servings of whole grains (like } \\
\text { whole grain bread or cereal, oatmeal, } \\
\text { brown rice, etc.) do you eat each day? }\end{array}$} \\
\hline 3 or more & $79(21.1)$ \\
\hline 2 & $156(41.7)$ \\
\hline 1 or less & $136(36.4)$ \\
\hline No response & $3(0.8)$ \\
\hline \multicolumn{2}{|c|}{$\begin{array}{l}\text { How many hours each day do you spend } \\
\text { watching TV or videos or on the } \\
\text { computer? }\end{array}$} \\
\hline More than 2 & $171(45.7)$ \\
\hline 1 to 2 & $139(37.2)$ \\
\hline Less than 1 & $61(16.3)$ \\
\hline No response & $3(0.8)$ \\
\hline \multicolumn{2}{|c|}{$\begin{array}{l}\text { How many times a week do you do yard } \\
\text { work or duties on the job that cause you } \\
\text { to work up a sweat? }\end{array}$} \\
\hline 4 or more & $180(48.1)$ \\
\hline 1 to 3 & $138(36.9)$ \\
\hline Less than 1 & $52(13.9)$ \\
\hline \multirow[t]{2}{*}{ No response } & $3(0.8)$ \\
\hline & Invalid (1 response) \\
\hline \multicolumn{2}{|c|}{$\begin{array}{l}\text { How many times a week do you get out } \\
\text { for a brisk walk of } 10 \text { minutes or more? }\end{array}$} \\
\hline 4 or more & $125(33.4)$ \\
\hline 1 to 3 & $104(27.8)$ \\
\hline Less than 1 & $144(38.5)$ \\
\hline No response & $1(0.3)$ \\
\hline \multicolumn{2}{|c|}{$\begin{array}{l}\text { How many times a week do you } \\
\text { participate in sports or an exercise } \\
\text { program? }\end{array}$} \\
\hline 4 or more & $54(14.4)$ \\
\hline 1 to 3 & $76(20.3)$ \\
\hline Less than 1 & $242(64.7)$ \\
\hline \multirow{2}{*}{ No response } & $1(0.3)$ \\
\hline & Invalid (1 response) \\
\hline
\end{tabular}


could cause cancer $(98.7 \%)$. In contrast, participant responses were more varied for the question as to whether being overweight causes cancer with $40.9 \%$ responding that being overweight could cause cancer, $21.9 \%$ responding that being overweight could not cause cancer, and $36.6 \%$ responding that they did not know whether being overweight could cause cancer. Thus, over $58 \%$ of participants were unaware of research linking obesity to cancer risk.

Table 3 shows that for fruit or vegetable consumption, only $6.4 \%$ of participants consumed five or more servings a day, and $54.3 \%$ consumed two or less servings a day. About $21 \%$ of participants consumed three or more servings of whole grains a day, while $42 \%$ and $36 \%$, respectively, reported that they had two servings or one or less servings. When asked how many sugary drinks a participant drank each day, the results were divided with the majority $(46.3 \%)$ responding that they consumed one to two drinks, $20.9 \%$ consumed three or more, and $32.6 \%$ consumed none (data not shown).

Participants were asked how many hours a day of "screen time" (watching television/videos or using the computer) they had. Over $45 \%$ responded that they watched more than two hours a day, $37.2 \%$ watched one to two hours a day, and $16.3 \%$ watched less than one hour per day (data not shown). In terms of physical activity, $48.1 \%$ of the participants indicated they did four or more hours of yard work or duties on the job that cause them to work up a sweat (Table 3). When asked how many times a week they went for a brisk walk of 10 minutes or more, the responses were divided across the response options as $33.4 \%$ responded four or more times, $27.8 \%$ one to three times, and $38.5 \%$ less than one time. The majority of the participants (64.7\%) engaged in a sports or exercise program less than one time a week.

Spearman's rank correlation was used to determine the relationship between BMI and the survey variables involving fruit, vegetable, whole grain, and physical activity (data not shown). There were no significant correlations between BMI and fruit, vegetables, and whole grain servings in either gender (Table 4). The majority of respondents, regardless of BMI group, did not consume the recommended levels of fruits, vegetables, and whole grains. Using chi-square analysis, BMI of the total sample was examined in relation to differences in sugarsweetened beverages (data not shown). There were no significant differences with BMI categories and sugarsweetened beverage consumption.

In terms of physical activity levels, there were no significant correlations between a male's BMI and how many hours a week he did yard work or duties on the job to work up a sweat, times a week he went out for a brisk walk of 10 minutes or more, and the number of times he participated in a sports or exercise program (Table 4).
Table 4. Associations of fruit, vegetable, whole grain intakes, and physical activity with body mass index (BMI) and waist circumference $(\mathrm{WC})^{\mathrm{b}}$ in total sample and by gender $(\mathrm{N}=374)$.

\begin{tabular}{|c|c|c|c|c|c|c|c|}
\hline \multirow[t]{2}{*}{ Behaviors } & \multicolumn{3}{|c|}{$\begin{array}{c}\text { Total } \\
(\mathrm{N}=374)\end{array}$} & \multicolumn{2}{|c|}{$\begin{array}{c}\text { Males } \\
(\mathrm{N}=125)\end{array}$} & \multicolumn{2}{|c|}{$\begin{array}{c}\text { Females } \\
(\mathrm{N}=249)\end{array}$} \\
\hline & & $r_{s}$ & $\mathrm{P}$ & $r_{s}$ & $\mathrm{P}$ & $r_{s}$ & $\mathrm{P}$ \\
\hline \multirow{2}{*}{$\begin{array}{l}\text { Servings of fruits } \\
\text { or vegetables per } \\
\text { week }\end{array}$} & $\mathrm{a}$ & 0.038 & 0.467 & -0.024 & 0.790 & 0.067 & 0.291 \\
\hline & $\mathrm{b}$ & 0.075 & 0.151 & -0.054 & 0.547 & 0.084 & 0.191 \\
\hline \multirow[t]{2}{*}{$\begin{array}{l}\text { Servings of whole } \\
\text { grains per week }\end{array}$} & $\mathrm{a}$ & -0.023 & 0.663 & -0.023 & 0.796 & -0.016 & 0.799 \\
\hline & $\mathrm{b}$ & -0.011 & 0.834 & -0.018 & 0.843 & -0.033 & 0.610 \\
\hline \multirow[t]{2}{*}{$\begin{array}{l}\text { Hours a week } \\
\text { doing yard work, } \\
\text { duties on the job } \\
\text { to work up a sweat }\end{array}$} & a & 0.015 & 0.770 & 0.024 & 0.791 & 0.012 & 0.853 \\
\hline & b & -0.018 & 0.735 & -0.036 & 0.695 & -0.028 & 0.661 \\
\hline
\end{tabular}

Times a week going out for a

brisk walk of 10 minutes or more

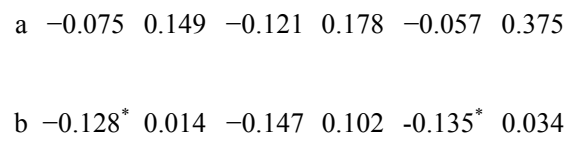

Times a week

$\begin{array}{llllllll}\text { participated in a } & \text { a }-0.194^{*} & 0.000 & -0.119 & 0.186 & -0.235^{*} & 0.000\end{array}$ program

b $-0.227^{*} 0.000-0.189^{*} 0.035-0.297^{*} 0.000$

${ }^{*}$ Significant at $\mathrm{P}<0.05 ; \mathrm{r}_{\mathrm{s}}$ : Spearman's rank correlation coefficient; $\mathrm{P}$ : P-value.

However, females showed a significant negative correlation between BMI and the number of times they participated in a sports or exercise program $\left(\mathrm{r}_{\mathrm{s}}=-0.235, \mathrm{P}<0.001\right)$, but did not have significant correlations in the number of hours a week they did yard work or duties on the job to work up a sweat, or the number of times a week they went out for a brisk walk of 10 minutes or more. Similarly, when the total number of participants was evaluated, there also was a significant negative correlation between BMI and the number of times a week participants engaged in a sports or exercise program $\left(\mathrm{r}_{\mathrm{s}}=\right.$ $-0.194, \mathrm{P}<0.001)$. Obese participants $(72 \%)$ reported engaging in a sports or exercise program less than one time a week compared to $46 \%$ of normal weight participants. When the total sample and each gender were analyzed, there were no significant correlations between BMI group and amount of screen time (data not shown).

There were no significant correlations between any of the diet measures and WC (data not shown). The only significant correlations of fruits, vegetables, whole grain intakes and physical activity with WC for the total sample were the physical activity behaviors involving the brisk walks $\left(\mathrm{r}_{\mathrm{s}}=-0.128, \mathrm{P}=0.014\right)$ and participation in the sports/exercise programs $\left(\mathrm{r}_{\mathrm{s}}=-0.227, \mathrm{P}<0.001\right)$ 
(Table 4). For females and males, a significant negative correlation was determined for WC and the times a week they participated in a sports or exercise program $\left(\mathrm{r}_{\mathrm{s}}=\right.$ $-0.297, \mathrm{P}<0.001 ; \mathrm{r}_{\mathrm{s}}=-0.189, \mathrm{P}=0.035$, respectively). There was a significant correlation with a female's WC and the number of times a week they went out for a brisk walk of 10 minutes or more $\left(r_{\mathrm{s}}=-0.135, \mathrm{P}=0.034\right)$.

\section{DISCUSSION}

This study examined food intake and physical activity behaviors and anthropometrics in two rural West Texas communities as an important first step in assessing cancer risk and intervention needs. People in rural areas may have greater health disparities due to limited access to facilities of primary health care and limited access to healthy foods and physical activity options $[4,16]$. Over $38 \%$ of the participants in this study were Hispanic, and they had a higher combined prevalence of overweight and obesity (84\%) compared to $78.7 \%$ for whites. Data from NHANES, BRFSS, and the Add Health study showed that minority groups had a higher combined prevalence than non-Hispanic whites by almost 10 percentage points [17].

A 2004 report found that $80 \%$ of rural residents were either overweight or obese which is similar to our study [18]. Prevalences in our study were considerably higher than those of state and national data: in 2010, the combined prevalence of overweight and obesity in Texas adults was $66.5 \%$ and nationally, this prevalence was $63.7 \%$ [19]. Thus, the prevalence of overweight and obesity in the rural areas in our study are a "call to action" for more population-based strategies to improve social and physical environmental contexts for healthful eating and physical activity [2].

We hypothesized that BMI and WC would be inversely associated with intake of fruits, vegetables, and whole grains and directly associated with intake of sugarsweetened beverages; however, our chi-square tests and Spearman's correlations were not significant. Overall, the participants in this study in every BMI and WC category reported a low consumption of fruits, vegetables, and whole grains; thus, no statistically significant associations were found. This is similar to a previous study noting that people in rural areas do not meet the recommendations for fruit and vegetable intake and are consuming even fewer servings than the national average [20]. Some determinants that may play a role in fruit and vegetable consumption may include individual demographic and socioeconomic factors, eating behaviors, access to healthy foods and environmental and social influences [20]. Food sources are often not evenly distributed in rural areas, and residents may experience loss of grocery stores and greater travel distances to obtain food [20]. The percentage of the participants in this study who reported consuming five or more fruits and vegetables a day was $6.4 \%$ which is considerably lower than BRFSS (2009) data for Texas that shows $23.8 \%$ of people consume fruits and vegetables five or more times per day [19]. More specifically, in nearby urban Lubbock, Texas, $27.4 \%$ reported consuming fruits and vegetables five or more times per day [19]. This draws an important contrast between urban and rural intakes.

An analysis of whole grain consumption in a national sample in the US showed that less than $5 \%$ of adults aged 19 to 50 years consumed three or more servings of whole grains per day [21]. This percentage is less than the percentage found in our study, with $21.1 \%$ of participants reporting consuming three or more servings of whole grains per day. A study in rural communities in Wyoming, Montana, and Idaho showed that individuals with high BMIs were less likely to eat high fiber cereal which is consistent with the assertion that nutrient dense diets that provide adequate levels of dietary fiber increase the likelihood of maintaining a normal body weight [22].

It was hypothesized in our study that BMI and WC would be correlated with higher consumption of sugarsweetened beverages; however, chi-square tests did not show significant associations among males or females, or among the total study group. Most overweight and obese participants, both males and females, reported consuming more than one sugary drink per day. It is also important to take into account that in our study, we did not specifically ask the portion size of the sugary drinks consumed which could underestimate or overestimate the total ounces the participants actually consumed. Other studies show that a higher frequency of sugar-sweetened beverage consumption among rural residents was associated with a higher BMI [20].

Nationally, the percentage of adults who are physically inactive is estimated to be $25.4 \%$, and in Bailey (Muleshoe) and Dallam (Dalhart) County, it was $26.4 \%$ and $25.8 \%$, respectively in 2008, according to BRFSS data and data from the US Census Bureau's Population Estimates Program [23]. Rural participants tend to have lower frequencies of physical activity compared to their urban counterparts $[10,22]$. The study by Liebman et al. showed that a self-reported frequency of participation in physical activity among rural participants was a significant predictor of obesity but not overweight [22]. Participants of that study were knowledgeable about the relationship between physical activity and maintenance of body weight, with respondents of high BMIs perceiving that lack of exercise was causally related to being overweight [22].

We hypothesized that BMI and WC would be inversely correlated with physical activity. This was partially supported by three findings: 1) an inverse correla- 
tion between BMI and the times a week female and total participants engaged in a sports or exercise program; 2) an inverse correlation between WC and male, female, and total participants for the times a week they engaged in a sport or exercise program; and 3) an inverse correlation between WC with female and total participants and the times a week they went for a brisk walk of 10 minutes or more. A randomized controlled trial determined the effects of different amounts and intensities of exercise training in an eight-month exercise program, in sedentary, overweight men and women to potentially prevent weight gain and even promote modest weight loss [24]. They found a significant dose-response relationship between amount of exercise and amount of weight loss and fat mass loss. Their observed relationships between exercise amount and weight loss, body composition changes, and decreases in measures of central adiposity note the importance of exercise in achieving effects in these particular areas.

Attributes of the physical environment may impact physical activity. Among urban residents, there is a notably increased likelihood to meet physical activity recommendations with an increase in the number of places available to exercise [10]. The participants in our study had divided responses between how many times they went for brisk walks a week. About 33\% responded that they went on brisk walks four or more times a week. Such strategies to address physical activity barriers in rural communities are essential in lowering the risk of higher BMI and other co-morbidities. An effective strategy in promoting weight loss and reducing fat mass has been seen by combining dietary restriction and physical activity [25]. There may be difficulty in individuals engaging in formal physical activity programs due to low financial resources or difficulty with transportation, which is why home-based exercise programs have also been investigated [25]. Efforts should be made to do a community assessment of physical activity resources in the two cities surveyed. Some resources of physical activity include private recreational facilities, health clubs, indoor gyms, places of worship or schools, trails, parks, and having destinations of walkable distance [10]. Research supports the importance of policies and promotion of nutrition and physical activity community resources to support individual-level health promotion interventions, and it is important to understand how to promote use of policy in high risk populations [26]. A study in eastern North Carolina, that promoted use of community resources, had participants identify physical activity community resources such as school tracks, local recreation centers/fitness programs, and parks [26]. The CDC has a guide for community-based approaches to promoting physical activity that may help in starting initiatives to planning physical activity outlets [27].
A surprising finding in our study related to the lack of participants' knowledge linking overweight and cancer risk. Most participants were aware that tobacco products and sunburns and the use of tanning beds could cause cancer; however, over $58 \%$ of participants were unaware that being overweight is related to cancer risk as shown by their "No" or "Don't Know" responses. This is comparable to a study identifying the knowledge of risk factors of overweight of Women, Infants, and Children (WIC) participants, with $67 \%$ strongly disagreeing that being overweight or obese increases cancer risk [28]. Many of the WIC participants also were not very aware of different foods' nutritional values with $80.2 \%$ of participants indicating that they were "Not at all" "Somewhat" or "Moderately" aware. According to the 2011 Food \& Health Survey: Consumer Attitudes Toward Food Safety, Nutrition \& Health commissioned by the International Food Information Council Foundation (IFIC), only one in ten people correctly estimated how many calories they should consume per day [29]. Other information from the survey showed that Americans do not regularly keep track of calories consumed or calories burned, and significantly fewer Americans were concerned with their weight status in 2011. These factors can ultimately affect weight management and cancer prevention.

Community-engaged approaches have gained increasing attention in research for their capacity to expand the reach of translational intervention and implementation sciences to influence practices and policies for eliminating disparities [30]. These approaches include forming genuine partnerships and co-learning, capacity building of community members in research, and long-term partnership commitments. Community-based participatory research (CBPR) tries to begin with a research topic that is important to the community and to take actions within the community to improve health [31]. CBPR can help in improving health outcomes, enhancing community input and sparking novel ideas and approaches.

\subsection{Limitations and Strengths}

Some limitations should be noted. One limitation is that the dietary and physical activity level data are selfreported and are subject to recall inaccuracies and participants' possible inclination to provide socially desirable responses. Also, the study participants may not be representative of their rural community or of other rural communities in other parts of the US. A third limitation is that the study may not be able to be replicated because of the differences in environment of the community and cultural differences among the communities' participants. Finally, although the AIM-HI Fitness Inventory has been used by clinicians and physicians, it has not been validated in community settings with diverse populations or 
tested for internal reliability.

There are several methodological strengths to this study. First, data captured a comprehensive look of participants' attitudes and awareness of cancer risks, and characteristics of their food consumption and physical activity. In addition, height, weight, and waist circumference were measured instead of using self-reported data. Finally, a health assessment with anthropometric data helped profile two rural communities that had not been previously studied.

\subsection{Implications}

Participants' lack of knowledge about the relationship between excessive weight and cancer risk should be addressed in order to motivate behavior change in both food intake and physical activity. The significant negative association between a female's BMI and the BMI of the total sample with number of times a week they participated in a sports or exercise program emphasizes the significance that exercise programs can have in a rural community. It would be desirable to investigate the effects of a sport or exercise program in a rural community and note the health changes that could occur in BMI, WC, changes in consumption of more healthful foods, or lowered risks to cancer and other chronic conditions. The findings that participation in sports and exercise programs and engaging in brisk walking even 10 minutes a day are associated with lower BMI and WC can be translated into educational messages that may be motivating to those who are trying to manage their weight.

Completing a community assessment to identify additional sites for recreational physical activity could ultimately lower the barrier of disparities between rural and urban communities. There also should be an increased emphasis in determining the factors that are influencing the low intake of fruits, vegetables and whole grains and high intake of sugar-sweetened beverages, such as lack of knowledge of their relationship to health, availability, and accessibility in terms of convenience and cost.

Focus groups and town hall meetings can help with communicating ideas, as well as seeing the variety of skills and needs across communities [32]. Planning within a community is an essential step in community member empowerment. Since overweight and obesity are prevalent in rural communities, preventing obesity in young children is recommended [2]. School food service programs that provide more fruits, vegetables, and whole grains and reduce access to sugar-sweetened beverages will help reduce the obesigenic environment [2]. Enhanced physical activity in physical education classes and classroom-based health education may help with the prevention of childhood obesity [2,33]. For adults, other innovations such as weight-loss programs broadcast over cable television may be able to address barriers that some rural residents may have with limited access to weightloss programs or centers. Other methods in promoting more weight and health management include developing community incentive programs for worksite weight management or nutrition programs and activities for the community.

\section{CONCLUSION}

This study increases our knowledge of characteristics of rural communities in West Texas and provides a profile of certain food consumption behaviors, physical activity levels, and cancer risk knowledge. Results from this study provide more information and understanding of what type of interventions would be important to address in these areas which are more vulnerable to health disparities. Involving the target population in determining intervention strategies will be important to intervention feasibility and success. A community-based research approach may help with furthering initiatives as partnerships could be formed with community members, health providers, and policymakers of the community. Furthermore, this study will inform future intervention targets and best practices for rural communities in West Texas and possibly other rural regions in the United States.

\section{ACKNOWLEDGEMENTS}

This project was funded by the Cancer Prevention Research Institute of Texas (CPRIT).

\section{REFERENCES}

[1] American Cancer Society (2013) Cancer facts \& figures 2013. American Cancer Society, Atlanta.

[2] Tai-Seale, T. and Chandler, C. (2003) Nutrition and overweight concerns in rural areas: A literature review. In: Rural Healthy People 2010: A Companion Document to Healthy People 2010, 115-130.

[3] Reed, D.B., Patterson, P.J. and Wasserman N. (2011) Obesity in rural youth: Looking beyond nutrition and physical activity. Journal of Nutrition Education and Behavior, 43, 401-408. doi:10.1016/j.jneb.2010.12.005

[4] Bustillos, B., Sharkey, J.R., Anding, J. and McIntosh, A. (2009) Availability of more healthful food alternatives in traditional, convenience, and nontraditional types of food stores in two rural Texas counties. Journal of the American Dietetic Association, 109, 883-889. doi:10.1016/j.jada.2009.02.011

[5] Lin, J., Zhang, S.M., Cook, N.R., et al. (2005) Dietary intakes of fruit, vegetables, and fiber, and risk of colorectal cancer in a prospective cohort of women (United States). Cancer Causes \& Control, 16, 225-233.

[6] US Department of Agriculture (2011) Dietary guidelines for Americans 2010. http://www.cnpp.usda.gov/

[7] Center for Disease Control and Prevention (2011) State- 
specific trends in fruit and vegetable consumption among adults-United States, 2000-2009.

http://www.cdc.gov/mmwr/preview/mmwrhtml/mm5935a $1 . h$ tm

[8] Pereira, M.A. (2006) The possible role of sugar-sweetened beverages in obesity etiology: A review of the evidence. International Journal of Obesity, 30, S28-S36. doi:10.1038/sj.ijo.0803489

[9] McTiernan, A., Kooperberg, C., White, E., et al. (2003) Recreational physical activity and the risk of breast cancer in postmenopausal women: The women's health initiative cohort study. Journal of the American Medical Association, 290, 1331-1336.

doi:10.1001/jama.290.10.1331

[10] Frost, S.S., Goins, R.T., Hunter, R.H., et al. (2010) Effects of the built environment on physical activity of adults living in rural settings. American Journal of Health Promotion, 24, 267-283. doi:10.4278/ajhp.08040532

[11] Martin, S.L., Kirkner, G.J., Mayo, K., Matthews, C.E., Durstine, J.L. and Hebert, J.R. (2005) Urban, rural, and regional variations in physical activity. The Journal of Rural Health, 21, 239-244. doi:10.1111/j.1748-0361.2005.tb00089.x

[12] Texas Tech University Health Science Center (2011) Demographic and economic maps. http://www.gis.ttu.edu/center/cgstARCH

[13] Center for Disease Control and Prevention (2011) Assessing your weight. http://www.cdc.gov/healthyweight/assessing/index.html

[14] Centers for Disease Control and Prevention (2011) Behavioral risk factor surveillance system survey questionnaire. http://www.cdc.gov/brfss/

[15] McAndrews, J.A., McMullen, S. and Wilson, S.L. (2011) Four strategies for promoting healthy lifestyles in your practice. Family Practice Management, 18, 16-20.

[16] McLafferty, S. and Wang, F. (2009) Rural reversal? Rural-urban disparities in late-stage cancer risk in Illinois. Cancer, 115, 2755-2764. doi:10.1002/cncr.24306

[17] Wang, Y. and Beydoun, M.A. (2007) The obesity epidemic in the United States-Gender, age, socioeconomic, racial/ethnic, and geographic characteristics: A systematic review and meta-regression analysis. Epidemiologic Reviews, 29, 6-28. doi:10.1093/epirev/mxm007

[18] Patterson, P.D., Moore, C.G., Probst, J.C. and Shinogle, J.A. (2004) Obesity and physical inactivity in rural America. Journal of Rural Health, 20, 151-159. doi:10.1111/j.1748-0361.2004.tb00022.x

[19] Centers for Disease Control and Prevention (2009-2010) Behavioral risk factor surveillance system survey data. US Department of Health and Human Services, Centers for Disease Control and Prevention, Atlanta.

[20] Johnson, C.M., Sharkey, J.R. and Dean, W.R. (2010) Eating behaviors and social capital are associated with fruit and vegetable intake among rural adults. Journal of Hunger \& Environmental Nutrition, 5, 302-315. doi:10.1080/19320248.2010.504094

[21] O’Neil, C.E., Nicklas, T.A., Zanovec, M. and Cho, S. (2010) Whole-grain consumption is associated with diet quality and nutrient intake in adults: The National Health and Nutrition Examination Survey, 1999-2004. Journal of the American Dietetic Association, 110, 1461-1468. doi:10.1016/j.jada.2010.07.012

[22] Liebman, M., Pelican, S., Moore, S.A., et al. (2006) Dietary intake-, eating behavior-, and physical activity-related determinants of high body mass index in the 2003 Wellness IN the Rockies cross-sectional study. Nutrition Research, 26, 111-117. doi:10.1016/j.nutres.2005.11.002

[23] Centers for Disease Control and Prevention: National Diabetes Surveillance System (2012) County level estimates of leisure-time physical inactivity-US. http://apps.nccd.cdc.gov/DDTSTRS/default.aspx

[24] Slentz, C.A., Duscha, B.D., Johnson, J.L., et al. (2004) Effects of the amount of exercise on body weight, body composition, and measures of central obesity: STRRIDE - A randomized controlled study. Archives of Internal Medicine, 164, 31-39. doi:10.1001/archinte.164.1.31

[25] Mediano, M.F.F., Barbosa, J., Moura, A.S., Willett, W.C. and Sichieri, R. (2010) A randomized clinical trial of home-based exercise combined with a slight caloric restriction on obesity prevention among women. Preventive Medicine, 51, 247-252. doi:10.1016/j.ypmed.2010.07.012

[26] Jilcott, S.B., Vu, M.B., Morgan, J. and Keyserling, T.C. (2012) Promoting use of nutrition and physical activity community resources among women in a family planning clinic setting. Women \& Health, 52, 55-70. doi: $10.1080 / 03630242.2011 .637612$

[27] Center for Disease Control and Prevention (2011) Physical activity. http://www.cdc.gov/physicalactivity/

[28] Adedze, P., Chapman-Novakofski, K., Witz, K., Orr, R. and Donovan, S. (2011) Knowledge, attitudes, and beliefs about nutrition and childhood overweight among WIC participants. Family \& Community Health, 34, 301-310. doi:10.1097/FCH.0b013e31822b53dd

[29] International Food Information Council Foundation (IFIC) (2012) 2011 food \& health survey. http://www.foodinsight.org

[30] Wallerstein, N. and Duran, B. (2010) Community-based participatory research contributions to intervention research: The intersection of science and practice to improve health equity. American Journal of Public Health, 100, S40-S46. doi:10.2105/AJPH.2009.184036

[31] Horowitz, C.R., Robinson, M. and Seifer, S. (2009) Community-based participatory research from the margin to the mainstream: Are researchers prepared? Circulation, 119, 2633-2642. doi:10.1161/CIRCULATIONAHA.107.729863

[32] Brownson, R.C., Baker, E.A., Boyd, R.L., et al. (2004) A community-based approach to promoting walking in rural areas. American Journal of Preventive Medicine, 27, 2834. doi:10.1016/j.amepre.2004.03.015

[33] HEALTHY Study Group, Mobley, C.C., Stadler, D.D., et al. (2012) Effect of nutrition changes on foods selected by students in a middle school-based diabetes prevention intervention program: The HEALTHY experience. Journal of School Health, 82, 82-90.

doi:10.1111/j.1746-1561.2011.00670.x 